\title{
Asbestos and Its Toxicological Concern
}

\section{Senthil Kumar Kurunthachalam*}

Department of Natural Sciences, Savannah State University, Savannah, GA 31404, USA

Asbestos or amianthus are a mixture of six or more fiber crystals such as amosite, amphibole, chrysotile (this alone contributes $90 \%$ of production all over the world), crocidolite, serpentine and other asbestiform materials (e.g., actinolite, richterite, tremolite and winchite) which were mixed with cement and can be molded and worn into fabrics. The chemical form of asbestos contains silicon, oxygen and minerals such as silicate compounds. Usage of asbestos begins more than 4000 years before (become familiar during the World War II). The commercial application was adopted from the 19th Century and continued usage found to be a primary concern of elevated air pollution in the developing parts of the world. Application of asbestos has been banned and restricted in industrialized countries based on the reports of lung related diseases by Lynch and Smith in 1935 followed by the annual report by Chief Inspector of Factories in Great Britain in 1955 [1] and numerous scientific publications relating asbestos pollution. Usage of asbestos is very general and still in the steady pace of use in developing countries (e.g., China, India, Kazakhstan etc.,) due to its resistance to fire and chemicals and medium tensile strength. Consequently, asbestos has been adopted in building materials, insulating media, safety clothing for firefighters, hot water piping, floor, ceiling and roof tiles or shingles, electrical insulation, sound absorption, furnace, friction products, automobile (e.g., brake pads), gaskets, cement products, textiles, coatings, plastics, gloves, heat-resistant clothing and packaging materials. Although the 'west' banned these debatable fibers; however, some countries (e.g., Canada export $>70 \%$ of India's requirement) still exports the asbestos related raw goods to the 'east' [2].

Asbestos found everywhere in the air, water and soil with minute concentrations and everyone gets exposed during the life time. Exposure of asbestos through water and soil is negligible. Its negative implications get started only during continuous exposure by occupational workers in the asbestos mining, milling and asbestos oriented occupation (i.e., cutting, drilling, trimming, and any mechanical modifications of finished or unfinished asbestos products). Besides, asbestos fibers can be detected highly in the following sectors such as asbestos fabric/textile producers, asbestos oriented materials producers, building and road construction, shipbuilding, insulation works, firefighters, demolition areas, drywall breaking, building demolition (e.g., Twin Tower, World Trade Center in New York city) and automobile industry. The finished products of asbestos do not pose any health risk to individual since air asbestos concentration remains low and intact. When it is damaged or broken during processing the tiny fibers of asbestos became airborne and can be inhaled at a significant rate. Besides, asbestos also releases fibers when it crumbled and stuck in the lungs. Therefore, after 20 to 30 years of exposure (latent period) to asbestos fibers the symptoms of lung related issues may begin.

Immediately after the inhalation, asbestos fibers have accumulated on the epithelial cell surface in the respiratory passage. Particularly, short-thick fibers $(>3 \mathrm{~mm})$ are settled in the upper respiratory tract, while long-thin fibers travels up to inner alveolar regions. Particles accumulate in the upper respiratory passage is transported by mucociliary action to the pharynxes, which is swallowed. On the other hand, short fibers are ingested by macrophages and removed through phagocytosis. Further longer fibers are cleared only after fragmentation, splitting or dissolution and retained in the lungs for a long time. Due to the differences in structure and length, chrysotile has high affinity to be deposited in the upper airways of the respiratory tract and also cleared efficiently from the lungs compared with amphibole fibers [3]. Shorter fibers retained in the lungs for prolonged periods and further they penetrate the epithelial cells into the lymphatic system or the blood and simultaneously reach kidney and gets excreted.

Asbestos enter into a person by breathing and deposited in lung tissues and accumulates over time and causes irritation, scarring and inflammation and eventually produces severe health implications [49]. Therefore, asbestos has been classified as human carcinogens. A history of asbestos exposure at occupational exposure is reported in about $70 \%$ to $80 \%$ of all cases of mesothelioma (a rare type of cancer of the mesothelium-the membrane that covers and protects most of the internal organs of the body). The main symptoms of mesothelioma of the lungs are shortness of breath, chest pain and abdominal mesothelioma include weight loss, swelling and pain in the abdomen, blood clotting abnormalities, bowel obstruction, anemia and fever. Continued exposure to high levels of asbestos in the occupational exposure scenario can also cause asbestosis (e.g., disease that can lead to disability and death and it scars the lungs and can cause the heart to enlarge). The primary symptoms of asbestosis are shortness of breath, persistent cough that produces mucus, chest tightness, chest pain, loss of appetite, dry, crackling sound in the lungs while inhaling followed by lung cancer with the symptoms of cough (including coughing up blood), wheezing, unexplained weight loss, difficulty breathing or shortness of breath, hoarseness and anemia. Clinical signs and symptoms of asbestosis include basal crackles on auscultation, dyspnea, cough and abnormal gas exchange, which may ultimately lead to death.

The prolonged asbestos fiber particle exposure is associated with severe health illnesses including pulmonary fibrosis, bronchogenic carcinoma, diffuse malignant, parenchymal asbestosis (prolonged inflammatory response stimulated by the presence of fibres in the lung, leading to fibrosis of the lung parenchyma and permanent damage to the lung system), mesothelioma of the pleura and peritoneum, pleural abnormalities such as effusions (excessive fluid collections in lung tissues and chest cavity), pleural plaques/thickening (changes in lung membrane and visceral pleura and discrete fibrous or calcified thickened areas that arise from the surface of the parietal pleura which is observed in 20 to 60 percent of the occupationally exposed

*Corresponding author: Senthil Kumar Kurunthachalam, Department of Natura Sciences, Savannah State University, Savannah, GA 31404, USA, E-mail: kuruntha@gmail.com

Received August 01, 2013; Accepted August 03, 2013; Published August 06, 2013

Citation: Kurunthachalam SK (2013) Asbestos and Its Toxicological Concern Hydrol Current Res 4: e110. doi:10.4172/2157-7587.1000e110

Copyright: (c) 2013 Kurunthachalam SK. This is an open-access article distributed under the terms of the Creative Commons Attribution License, which permits unrestricted use, distribution, and reproduction in any medium, provided the original author and source are credited. 
persons), parietal pleura, and it may be associated with cancer at extra thoracic sites and eventually end with malignant lung cancer [10-15]. Studies have put forward prolonged inhalation of asbestos may also increase the risk of gastrointestinal, throat, kidney, colorectal cancers, esophagus colon, rectum, vocal cords and gallbladder diseases [16].

Several studies have documented that combination of asbestos exposure and smoking can produce severe adverse health implications. Smokers who are also exposed to asbestos have a risk of developing lung cancer that is greater than the individual risks from asbestos and smoking added together [16,17]. There is evidence that quitting smoking will reduce the risk of lung cancer among asbestos-exposed workers [18]. Further all forms of asbestos are considered hazardous, different types of asbestos fibers may be associated with many health risks. For example, the results of several studies suggest that amphibole forms of asbestos may be more harmful than chrysotile, particularly for mesothelioma risk, because they tend to stay in the lungs for a longer period of time [19]. Toxicological perspectives of asbestos on individuals can be listed on the dose, the length (period) of exposure, physical an chemical nature of asbestos fiber exposed, source of exposure, personal risk factors such as smoking habits of genetic lung disease.

Laboratory studies revealed that asbestos fibers accumulated in the liver, kidney, heart, spleen and brain of the rats fed asbestos mixed diet and these results supports that fibers can pass into the gastrointestinal tract [19]. Other research with inhalation of asbestos in the rodents for the 2 week period produced local inflammatory lesions in the terminal bronchioles and progressive fibrosis occurred within a few weeks of exposure [20]. The study also reveals a single oral ingestion of chrysotile $(5-100 \mathrm{mg} / \mathrm{kg}$ ) fibers to the rats produced an increase in thymidine in the stomach, jejunum and duodenum, suggestive of an immediate response of cellular proliferation and DNA synthesis [20]. The Guinea pigs and monkeys were exposed to chrysotile and amosite dust for different exposure periods. In Guinea pigs either dusts produced, multitude of disease such as pulmonary fibrosis, interstitial pneumonitis, metaplasia of the epithelium of alveolar ducts, reticulum formation, lysosomal enzymes is released from membrane-bound latent state to active free form and pulmonary, metabolic machinery. The monkeys died after exposure to both chrysotile and amosite [20]. Overall, exposure to asbestos fibers may cause all four major types of lung cancer, namely squamous cell carcinoma, adenocarcinoma, largecell carcinoma and small-cell carcinoma [21]. Asbestos also produced to cardiovascular effects, gastrointestinal effects, immunological modifications, and genotoxicity (e.g., chromosome damage), reproductive toxicity in women to the asbestos workers. Chrysotile fibers have been reported in placenta, liver and lungs of stillborn infants hence the transplacental transfer of asbestos is thought to occur.

From the Asian continent, after China, India is emerging as the primary producer and user of asbestos where the developed world phasing out its use. In India, more than 25 asbestos producing mines is in active operation with a production rate of approximately 3,000 tonnes/month along with $>70$ percent of the quantity imported from Canada [10]. Asbestos imports to India accounted to be $>100,000$ metric tons/year in which small asbestos industries contribute almost 5 to 10 percent of the total country usage. Consequently, the epidemic of illness and death that has plagued the developed countries in the past will more likely to be repeated in developing Asian countries soon. Production and usage of asbestos occur in the states of Andra Pradesh, Bihar, Karnataka, Manipur, Rajastan and Tamil Nadu. Among them, Rajasthan state alone produces about $90 \%$ of the asbestos in which more than $50 \%$ of them being processed in unorganized sectors which consists of fugitive asbestosis producing dusts which is mostly deviate from international standards [22]. Therefore, environmental problems in India are largely due to a steady increase in population, industrial development, very poor environmental -awareness -policies, -management, and -commitment. Furthermore, poor occupational health and safety systems in India and difficulties in early detection of pulmonary malignancy related to asbestos. Indian government should consider the bans of this material in future to save $>100,000$ direct and indirect employees in asbestos related industry and mines in India [11]. Indian Association of Occupation Health (IAOH) took a strong and principled stand against the asbestos industry and many of its members requested for the asbestos ban in India [23]. Few professional agencies like National Institute of Occupational Health (NIOH), Industrial Toxicology Research Center (ITRC), Central Labor Institute (CLI) also working on issues like asbestos and its related diseases [24].

Dave and Beckett [6] have identified significant occupational exposures, early pleural and parenchymal changes on chest radiograph, and decrements in lung function with asbestos exposed workers in India. Other studies documented an increase in the deterioration of lung was observed in Tamil Nadu among the workers who is exposed to asbestos dust compared to the general workers in a manufacturing unit because quality of asbestos produced in India is very poor [25]. Joshi and Gupta [12] documented asbestos associated morbidity in India and believe that the growing strength of the movement against asbestos producers, it is expected that manufacturers may find it increasingly difficult to manipulate the government in the future in order to continue their fugitive lung cancer causing fiber production.

The asbestos cancer epidemic may take as many as 10 million lives before asbestos is banned worldwide and exposures are brought to an end. In many developed countries, in the most affected age groups, mesothelioma may account for $1 \%$ of all deaths. In addition to mesotheliomas, $5-7 \%$ of all lung cancers can be attributed to occupational exposures to asbestos [14]. Based on the International Labour Office (ILO) it is required to more than 100,000 deaths/ year may occur from asbestos-related disease. Other research from Australia, European countries and Japan published that the number of deaths will be maximized in and around 2020's ranged from half to one million. Particularly, more than a million deaths will occur in developing countries. Considering those toxicological perspectives of asbestos, the immediate action of using personal protective equipment (e.g., respirable mask) is warranted for the asbestos workers which would reduce the risks of asbestos related illness. Further complete ban on this debatable airborne crystal/fiber is needed in the each country in order to provide a safe life to the individuals.

\section{References}

1. Selikoff IJ, Churg J, Hammond EC (1964) Asbestos exposure and neoplasia. JAMA 6: 22-26.

2. Bartrip PW (2004) History of asbestos related disease. Postgrad Med J 80: 72-76.

3. International Programme on Chemical Safety (1986) Asbestos and other natural mineral fibres. Environmental Health Criteria 53: WHO, Geneva.

4. Rahman Q, Das B, Viswanathan PN (1983) Biochemical mechanisms in asbestos toxicity. Environ Health Perspect 51: 299-303.

5. Harris LV, Kahwa IA (2003) Asbestos: old foe in 21st century developing countries. Sci Total Environ 307: 1-9.

6. Dave SK, Beckett WS (2005) Occupational asbestos exposure and predictable asbestos-related diseases in India. Am J Ind Med 48: 137-143. 
7. Bull S, CHAPD HQ HPA (2007) HPA ASBESTOS toxicological overview.

8. Lee KP (1985) Lung response to particulates with emphasis on asbestos and other fibrous dusts. Crit Rev Toxicol 14: 33-86.

9. Kini U, Shariff S, Thomas JA (1992) Primary pleural mesotheliomas in south India: a 25-year study. J Surg Oncol 49: 196-201.

10. Ramanathan AL, Subramanian V (2001) Present status of asbestos mining and related health problems in India--a survey. Ind Health 39: 309-315.

11. Joshi TK, Gupta RK (2004) Asbestos in developing countries: magnitude of risk and its practical implications. Int J Occup Med Environ Health 17: 179-185.

12. Joshi TK, Gupta RK (2003) Asbestos-related morbidity in India. Int J Occup Environ Health 9: 249-253.

13. Agnihotram RV (2005) An overview of occupational health research in India Indian J Occup Environ Med 9: 10-14.

14. LaDou J (2004) The Asbestos Cancer Epidemic. Environ Health Perspect 112 285-290.

15. Agency for Toxic Substances and Disease Registry (2012) Case Studies in Environmental Medicine (CSEM) Asbestos Toxicity.

16. National Toxicology Program (2005) Asbestos, In: Report on Carcinogens. Eleventh Edition, U.S. Department of Health and Human Services, Public Health Service, National Toxicology Program.

17. Agency for Toxic Substances and Disease Registry (2009) Asbestos: Health Effects.
18. Ullrich RL (2004) Etiology of cancer: Physical factors. In: Cancer: Principles and Practice of Oncology, ed. DeVita VT Jr, Hellman S, Rosenberg SA, Philadelphia: Lippincott Williams and Wilkins, 1: 2.

19. Agency for Toxic Substances and Disease Registry (2001) Toxicological Profile for Asbestos.

20. Risk Assessment Information System (1995) Toxicity summary for asbestos Chemical Hazard Evaluation and Communication Group, Biomedical and Environmental Information Analysis Section, Health and Safety Research Division.

21. Agency for Toxic Substances and Disease Registry (1997) Case studies in environmental medicine: Asbestos toxicity. US Department of Health and Human Services. Atlanta, US.

22. Ansari FA, Ahmad I, Ashquin M, Yunus M, Rahman Q (2007) Monitoring and identification of airborne asbestos in unorganized sectors, India. Chemosphere 68: 716-723.

23. Castleman B (2001) Heroism in occupational health. Int J Health Serv 31: 669672.

24. Saiyed HN, Tiwari RR (2004) Occupational health research in India. Ind Health 42: $141-148$.

25. Gautam AK, Yunus M, Rahman A, Reddy SS (2003) Environmental monitoring of asbestos products manufacturing units--a case study. Indian $\mathrm{J}$ Environ Health 45: 289-292. 